\title{
CHANTAL MOUFFE
}

\section{El liberalismo norteamericano y sus críticos: Rawls, Taylor, Sandel, Walzer*}

\begin{abstract}
A partir de Tocqueville, los Estados Unidos son considerados a menudo como la tierra predilecta del liberalismo democrático. Desde la constitución de 1787, el liberalismo habría podido florecer en Norteamérica sin chocar con los obstáculos que debió vencer en los países europeos. Reformulado por Louis Hartz en su libro de 1955, The Liberal tradition in America, este tema gozó durante mucho tiempo de una hegemonía indiscutida, y es a esta característica que se atribuía la doble ausencia, tanto de una real tradición conservadora, como de un importante movimiento socialista en Norteamérica. Muchos veían igualmente en ello el secreto de la fuerza y de la vitalidad del Nuevo Mundo. Sin embargo, desde hace algunos años, parece que los norteamericanos son cada vez más críticos con respecto a este predominio del liberalismo democrático; es así como algunos se pusieron a buscar otras formas de identidad y comenzaron a escrutar su pasado para descubrir en él los signos de la presencia de otras tradiciones.

Desde el fin de los años 60, se organizó un movimiento "neoconservador" l para alertar contra los "excesos de la democracia". Agitando el espectro del "precipicio igualitario", este grupo, compuesto por intelectuales prestigiosos agrupados alrededor de las revistas Commentary y The Public Interest, lanzó una ofensiva contra la ola democrática que los diversos movimientos sociales de esta década han representado. Los neo-conservadores denuncian la sobrecarga de demandas que la multiplicación de nuevos derechos impone al Estado y el peligro que esta explosión de reivindicaciones igualitarias hace correr al sistema de autoridad.

* Tomado de la revista Esprit, marzo de 1987. (Traducción de Nora Pasternac.)

l Encontramos entre ellos a Irving Kristol, Daniel Patrick Moynihan, Daniel Bell, Samuel Huntington y Zbigniew Brzezinski, para no citar sino a los más conocidos. Para un excelente análisis de este movimiento, se puede consultar el libro de Peter Steinfels, The NeoConservatives, Nueva York, 1979.
\end{abstract}


Más o menos por la misma época, un grupo de "neoliberales" la emprende contra las medidas de redistribución de la Great Society y denuncia la intervención del Estado en la economía. De acuerdo con Milton Friedman, preconizan un retorno al capitalismo de libre mercado. De un lado como del otro, lo que se ataca es, en realidad, la articulación entre liberalismo y democracia a causa del potencial subversivo de la idea democrática frente a la preservación de las relaciones sociales dominantes. ${ }^{2}$

Recientemente, una nueva voz se dejó oir: ya no es más la democracia el blanco de las críticas, sino el liberalismo básico, responsable de la destrucción de los valores comunitarios y del debilitamiento de la vida pública. Este tipo de crítica, que tiene a la vez acentos de izquierda y resonancias conservadoras, es original, pues opera en el marco del redescubrimiento de una tradición ocultada hasta hoy en los Estados Unidos: la del "republicanismo cívico". Esta tradición - que algunos prefieren llamar "humanismo cívico" - afirma en su discurso político que la verdadera realización humana sólo es posible cuando se actúa en tanto ciudadano de una comunidad política libre y autogobernada. Según Pocock -uno de los que más ha contribuido a la reconstrucción de estas ideas- los orígenes de semejante concepción deben buscarse en la visión aristotélica del hombre como zoon politikon, en Cicerón y en el ideal romano de la res publica. No obstante, es en Florencia, en el siglo XV, donde adquiere las características que van a influenciar al pensamiento político angloamericano de los siglos XVII y XVIII, a través de la obra de James Harrington y de los neo-harringtonianos. ${ }^{3}$ Se trata de un lenguaje político que realiza una síntesis entre elementos aristotélicos y maquiavélicos, lenguaje en el cual desempeñan un papel central las nociones de "bien común", "virtud cívica" y "corrupción".

Ahora bien, en el curso de las últimas décadas se produjo una reorientación espectular de la interpretación de la revolución norteamericana que puso en evidencia precisamente la importancia del republicanismo cívico en el periodo revolucionario.

2 Sobre esta ofensiva tanto de los liberales como de los neoconservadores contra la democracia, remitimos al lector a nuestro artículo "Democracy and the New Right", Politics and Power, No. 4, 1981, Londres.

3 J. G. A. Pocock, The Machiavellian Moment: Florentine Political Thought and the Allantic Republican Tradition, Princeton, N. J., 1975; Politics, Language and Time, Nueva York, 1973 y Virtue, Commerce and History, Cambridge, 1985. Sin embargo, hay que especificar que Pocock mismo no es de aquellos que proponen revivir la tradición del republicanismo ćvico actualmente. 
Contrariamente a la interpretación dominante, que veía en esta revolución una ruptura de tipo nacionalista con el Viejo Mundo, influenciada principalmente por las ideas de Locke, los trabajos de historiadores como Bailyn y Wood ${ }^{4}$ mostraron que había sido profundamente influenciada por la cultura del humanismo cívico neo-harringtoniano. De allí viene el lugar central que ocupa la noción de "corrupción" en el lenguaje político de los patriotas norteamericanos, como lo revela el análisis que hace Bailyn de sus panfletos. Sólo más tarde, la concepción clásica de la política, donde los individuos participan activamente en la res publica, va a deslizarse hacia un nuevo paradigma: el de la democracia representativa. De acuerdo con Gordon Wood, es la constitución federalista de 1787 la que marca el fin de la política clásica y la instauración de ese nuevo paradigma en el cual el pueblo ya no es conce bido como ligado por una comunidad de intereses, sino como "una aglomeración de individuos hostiles que se reúnen alrede-dor de su beneficio común en la construcción de una sociedad". ${ }^{5}$

Es en ese momento cuando desaparece la insistencia sobre la necesidad de la virtud pública y el bien común y aparece el concepto nuevo de opinión pública. Wood muestra cómo una nueva fórmula de gobierno hizo su aparición y cómo implicaba una concepción de la política en tanto compromiso entre intereses cuya formulación era exterior a la acción política misma. Esta nueva concepción, que en general se califica como "liberal", se convirtió en dominante durante el siglo XIX; aunque según algunos la concepción republicana no fue completamente borrada. Por ejemplo, Pocock ${ }^{6}$ afirma que persiste subterráneamente gracias al mantenimiento de valores y de símbolos pre-modernos y antiindustriales en la cultura norteamericana. A esta tradición van a apelar los autores críticos del individualismo liberal, afirmando que gracias a ella los norteamericanos pudieron conservar un cierto sentido de la comunidad que a su vez les permite resistir a los efectos corrosivos del individualismo. ${ }^{7}$ En la revitalización de esta tradición de republicanismo cívico ven la solución a la crisis

4 Bernard Bailyn, The ideological origins of the American Revolution, Cambridge, Mass., 1967 y The Origins of the American Politics, Nueva York, 1967; Gordon S. Wood, The Creation of the American Republic, 1776-1787, Chapel Hill, 1969.

5 Wood, op. cit., p. 607.

6 Pocock, The Machiavellian Moment, op. cit., p. 549

7 Ésta es la tesis defendida por Robert Bellah y sus colaboradores en Habits of the Herat, Individualism and Commitment in American Life, Berkeley, 1985, así como por William M. Sullivan en Reconstructing Public Philosophy, Berkely, 1982. 
que vive hoy la sociedad norteamericana. Una crisis que consiste, según ellos, en la destrucción del lazo social debida a la promoción social del individuo que sólo conoce la búsqueda de su interés propio y rechaza toda obligación que pudiera trabar su libertad. Mientras que los neo-conservadores ven en la idea democrática el origen de las dificultades del sistema liberal democrático, para los autores llamados "comunitarios" es central la desaparición de la virtud cívica, es decir, de la identificación a una comunidad política donde la ciudadanía entraña derechos pero también deberes. Esta desaparición es consecuencia de la privatización de la vida social así como de la desaparición del espacio público y no se puede remediar más que a través de una revaloración de la participación política. Actualmente, la ilusión liberal de que la armonía podría nacer del libre juego de los intereses particulares y que la sociedad moderna ya no tiene necesidad de la virtud cívica finalmente se mostró peligrosa: cuestiona la existencia misma del proceso democrático. De allí viene la necesidad de una nueva cultura política que reanude los lazos con la tradición del republicanismo cívico y devuelva su dignidad a lo político.

\section{Un nuevo paradigma liberal}

No es asombroso que los comunitarios actuales, como los neoconservadores de ayer, hayan elegido a John Rawls como blanco principal. En efecto, desde su publicación en 1971, $A$ Theory of Justice $e^{8}$ fue saludada como una obra magistral que instaura un "nuevo paradigma liberal". Este paradigma "deontológico" o rights-based (fundado en los derechos) puso fin a la supremacía indiscutida del utilitarismo en la reflexión teórica anglo-sajona, y toda crítica al liberalismo debe arreglar cuentas con aquello que es considerado como su elaboración más avanzada.

La posición de Rawls evolucionó de manera bastante sustancial desde la publicación de su libro, ${ }^{9}$ cosa que plantea algunos problemas para captar la coherencia de su teoría y juzgar las críticas que se le dirigen. A Theory of Justice daba a entender que Rawls buscaba un algoritmo de la elección Racional, un punto de Arquímedes que garantizara el carácter universal de su teoría de

8 John Rawls, $A$ Theory of Justice, Cambridge, Mass., 1971.

9 Dos artículos, sobre todo, hacen manifiesta esta evolucion de Rawls: "Kantian Constructivism in Moral Theory", The Journal of Philosophy, vol. LXXVII, No.9, septiembre de 1980 ,y "Justice as Fairness: Political not Metaphysical", Philosophy and Public Affairs, verano de 1985, vol. 14, 3. 
la "igualdad". Su problema consistía en determinar cuáles principios de justicia debían escoger las personas libres y racionales -si se colocaban en una situación de igualdad - para definir los términos fundamentales de su asociación. Más tarde, declaró que solamente deseaba elaborar una concepción de la justicia para las sociedades democráticas modernas partiendo de las instituciones comunes a los miembros de esas sociedades. Su objetivo era articular y hacer explícitas las nociones y principios presentes en estado latente en el sentido común: por lo tanto, no pretendía formular una concepción de la justicia que fuera "verdadera", sino proponer principios válidos para nosotros, en función de nuestra historia, de nuestras tradiciones, de nuestras aspiraciones y de la manera como concebimos nuestra identidad. ${ }^{10}$

Contrariamente al utilitarismo, Rawls no concibe a la persona como un puro individuo racional que busca exclusivamente su bienestar, sino como una persona moral susceptible, no sólo de acción "racional" (entendida como acción instrumental que apunta al propio interés), sino también de lo que se llama acción "razonable", que implica consideraciones morales y sentido de la justicia en la organización de la cooperación social. Es un método que él designa con el término de "constructivismo kantiano", a fin de indicar que opera con una concepción de la persona concebida, a la manera kantiana, como persona moral libre e igual.

Para un liberal de tipo kantiano como Rawls, que defiende una forma de liberalismo en la cual el derecho no debe depender de ninguna concepción utilitarista, es importante que lo que justifique al derecho no sea la "maximización" del bienestar general, ni ninguna otra concepción particular del bien. Por ello, afirma que lo razonable debe tener la prioridad sobre lo racional pues la exigencia de términos equitativos de cooperación debe limitar el margen de libertad que los individuos tendrán en la definición y la búsqueda de su interés propio. Eso significa que existirá "prioridad del derecho sobre el bien", es decir, prioridad de un marco de derechos y libertades fundamentales por sobre las diferentes concepciones del bienestar que les serán permitidas a los individuos. ${ }^{11}$ Rawls considera que no es justo acrecentar el bienestar total de una sociedad si eso implica sacrificar a un cierto número de personas. Hay que tratar a los individuos como fines en sí y no como medios, precepto que él reprocha al utilitarismo no respetar. En efecto, para esta teoría los individuos no son

10 Rawls, "Kantian Constructivism", op. cit., pp. 516-519.

11 Rawls, $A$ Theory of Justice, op. cit., pp. 446-452. 
más que unidades de cuenta en el cálculo de rendimiento máximo del interés general. Ahora bien, al sumar a los individuos se los homogeiniza y se sacrifican intereses privados en nombre de la utilidad de la mayoría. Rawls está seguro de garantizar la defensa de los derechos fundamentales de los individuos y su libertad de una manera mucho más completa que el utilitarismo, pues su teoría de la justicia está construida para respetar su pluralidad y su especialidad.

Sin embargo, para que el acuerdo sobre los principios de justicia sea verdaderamente equitativo, es necesario encontrar un punto de vista que no esté influenciado por las circunstancias particulares de los participantes y sus intereses. Ese es el papel que Rawls hace desempeñar a la "posición original", la cual, con su velo de ignorancia va a esconder a los participantes su lugar exacto en la sociedad, sus talentos, sus objetivos y todo lo que podría perjudicar a su imparcialidad. Esa posición va a servir de mediadora entre la concepción kantiana de la persona (a la cual Rawls espera poder liberar de la metafísica que la entorpece en Kant y redefinir en términos estrictamente empíricos) y los principios de justicia que se tratan de construir. La posición original designa, entonces, una situación heurística de igualdad y de libertad que va a permitir a los participantes seleccionar, con el procedimiento de deliberación, los principios de justicia para organizar la cooperación social entre personas libres e iguales. Por lo tanto, no hay criterio independiente de justicia y el propio procedimiento va a garantizar que el resultado producido sea justo. Este método de constructivismo kantiano conduce a formular los dos principios de justicia siguientes:

1. Cada uno debe tener un derecho igual a la libertad fundamental más extendida posible y compatible con una libertad idéntica para los otros.

2. Las desigualdades económicas y sociales deben ser establecidas de tal manera que: $a$. beneficien lo más posible a los desfavorecidos (es el famoso principio de la diferencia); $b$. estén adheridas a funciones y a posiciones abiertas a todo en condiciones equitativas de igualdad de oportunidades.

El primer principio tiene prioridad sobre el segundo y la cláusula $b$. sobre la cláusula $a$. de tal manera que no se debería legitimar ninguna restricción de libertad o de igualdad de oportunidades con el argumento de que contribuye a mejorar la suerte de los menos favorecidos. Rawls resume la concepción general de su teoría de la justicia de la manera siguiente: "Todos los bienes sociales primarios - libertad e igualdad de oportunidades, in- 
gresos y riquezas, así como las bases del respeto propio-deben ser distribuidos de manera igual, salvo si una distribución desigual de uno o del conjunto de esos bienes es en beneficio ventajoso de los menos favorecidos". ${ }^{12}$

Rawls considera que su teoría de la justicia aporta finalmente la respuesta a la pregunta tan controvertida de saber cuáles son los principios de justicia que deben reorganizar los términos de la cooperación social entre personas libres e iguales. Piensa haber logrado formular un principio rector que permita poner en acción los valores de igualdad y libertad en las instituciones sociales, resolviendo así el conflicto que dura desde hace dos siglos en el pensamiento democrático.

Sin embargo, semejante pretensión fue cuestionada muy pronto. Desde 1974, Robert Nozick, en Anarchy, State and Utopia, se apresuró a mostrar cómo se podía llegar a una concepción de la justicia diametralmente opuesta partiendo de una posición similar a la de Rawls. En efecto, mientras Rawls es un defensor indiscutido del Estado-Providencia, liberal democrático, al cual pretende justificar como la forma política más justa y racional, Nozick, es un defensor del estado mínimo, que sólo se limita a defender la ley y el orden y que rechaza todo tipo de función distributiva. Según Nozick la justicia social no existe, si la entendemos como justicia distributiva; además declara que una sociedad es justa en tanto sus miembros posean aquello a lo que tienen derecho, independientemente de las formas de repartición de la riqueza que eso implica. ${ }^{13}$

\section{El individualismo liberal cuestionado}

No tratamos aquí de analizar el conjunto del debate suscitado por la obra de Rawls, sino de examinar los argumentos de las críticas calificadas de "comunitarias". A través de Rawls y el nuevo paradigma que instauró, lo que esta crítica ataca es la filosofia misma del liberalismo en razón de su individualismo. Denuncia la concepción ahistórica, asocial y desencarnada del sujeto, que implica la idea de un individuo dotado de derechos naturales anteriores a la sociedad, y rechaza la tesis de la prioridad del derecho sobre el bien. Contra la inspiración kantiana de Rawls, los autores comunitarios hacen hablar a Aristóteles y a Hegel; contra el liberalismo apelan a la tradición del republicanismo cívico.

12 Ibid.p. 302.

13 Robert Nozick, Anarchy, State and Utopia, Nueva York, 1974, p. 7. 
Para Charles Taylor, la visión liberal de sujeto es "atomísti$\mathrm{ca}^{\mathrm{n}}{ }^{14}$ pues afirma el carácter autosuficiente del individuo: constituye un real empobrecimiento en relación con la noción aristótelica del hombre como animal fundamentalmente político, que no puede realizar su naturaleza humana más que en el seno de una sociedad. Taylor cree que esa concepción es el origen de la destrucción de la vida pública a través del desarrollo del individualismo burocrático. Según Taylor, gracias a la participación en una comunidad de lenguaje y de discurso mutuos que se refieren a lo justo y a lo injusto, al bien y al mal, puede desarrollarse la Racionalidad y el hombre puede convertirse en un sujeto moral capaz de buscar el bien; por lo tanto, no podría haber prioridad del derecho sobre el bien. Refiriéndose especialmente a Nozick, Taylor muestra lo absurdo de pretender partir de la prioridad de los derechos naturales a fin de deducir de ellos el conjunto del contexto social. En efecto, ese individuo moderno, con sus derechos, es el resultado de un largo y complejo desarrollo histórico y sólo en un cierto tipo de sociedad es posible la existencia de un individuo libre, capaz de escoger sus propios objetivos. ${ }^{15}$

Alasdair MacIntyre, ${ }^{16 !}$ por su parte, reprocha a Rawls y a Nozick que propongan una concepción de la justicia que no deja ningún lugar a la noción, para él fundamental, de "mérito": MacItyre atribuye esta incapacidad, a la concepción de una sociedad compuesta de individuos, cuyos intereses son definidos anterior e independientemente de la construcción de cualquier lazo moral o social entre ellos. Ahora bien, dice MacIntyre, la noción de mérito sólo tiene sitio en el contexto de una comunidad cuyo lazo originario es una comprensión compartida, tanto del bien para el hombre como del bien para la comunidad, y donde los individuos identifican sus intereses fundamentales con referencia a esos bienes. ${ }^{17}$, MacIntyre ve en el rechazo, por parte del liberalismo de toda idea de un "bien común", la fuente del nihilisimo que estaría destruyendo nuestras sociedades.

Sin embargo, es en Michel Sandel donde encontramos la crítica comunitaria con más consecuencias. En Liberalism and the Limits of Justice, ${ }^{18 \mid}$ Sandel se ocupa de realizar un análisis minucioso de

14 Charles Taylor, Philosophy and the Human Sciences; Philosophical Papers 2, Cambridge, 1985, capítulo 7, "Atomism".

15 Ibid., p. 200.

16 Alasdair MacIntyre, After Virtue, Notre Dame, 1984.

17 Ibid., p. 256.

18 Michael J. Sandel, Liberalism and the Limits of Justice, Cambridge, 1982. 
la teoría de la justicia de Rawls a fin de probar su carácter inconsistente. Ataca principalmente la tesis de la prioridad del derecho sobre el bien y la concepción de sujeto que implica. Si Rawls afirma que la justicia es la virtud primordial de las instituciones sociales, dice Sandel, es porque su liberalismo deontológico exige una concepción de la justicia que no presupone ninguna concepción particular del bien, a fin de poder servir de marco para que en su interior sean posibles diferentes concepciones del bien. En efecto, en la concepción deontológica, la primacía de la justicia no describe solamente una prioridad moral sino también una forma privilegiada de justificación. El derecho es anterior al bien, no sólo porque sus exigencias tienen prioridad, sino porque sus principios se derivan de manera independiente. ${ }^{19}$ Pero para que el derecho sea anterior al bien sería necesario que el sujeto existiera independientemente de sus intenciones y de sus fines. Semejante concepción requiere de un sujeto que pueda tener una identidad definida anteriormente a los valores y a los objetivos que va elegir. En efecto, es la capacidad de elegir (y no las elecciones que realiza) la que define semejante sujeto. Si no, no pueden existir jamás, fines que sean constitutivos de la identidad del sujeto, se le niega así la posibilidad de participar en una comunidad donde la definición misma de lo que él es está en juego: ${ }^{20}$

De acuerdo con Sandel, en la problemática de Rawls, semejante tipo de comunidad constitutiva es impensable, y la comunidad sólo puede ser concebida como simple cooperación entre individuos cuyos intereses están dados de antemano y que se reúnen $a_{\text {, }}$ fin de defenderlos y hacerlos progresar. Su tesis central es que esta concepción "desencarnada" del sujeto, incapaz de compromisos constitutivos, es necesaria para que el derecho pueda tener prioridad sobre el bien y, a la vez, contradictoria con los principios de justicia que Rawls pretende sustentar. En efecto, como el principio de diferencia es un principio de repartición, presupone la existencia de un lazo moral entre aquéllos que van a repartir los bienes sociales; por lo tanto, supone una comunidad constitutiva cuyas exigencias se reconocen. Ahora bien, precisamente este tipo de comunidad, declara Sandel, está excluído por la concepción de Rawls del sujeto sin ataduras y definido con anterioridad a los fines que escoge. En consecuencia, el proyecto de Rawls fracasa porque "no podemos ser al mismo tiempo personas para quienes la justicia es primordial y personas para quienes

19 Ibid., p. 15.

20 Ibid., p. 150. 
el principio de diferencia es un principio de justican. ${ }^{21}$

\section{Política de los derechos o política del bien común}

La crítica de Sandel se basa principalmente en la posición defendida por Rawls en $A$ Theory of Justice y no toma en cuenta la evolución ulterior de su pensamiento, mientras que sobre varios puntos los artículos recientes modifican su concepción del sujeto de manera bastante sustancial. ${ }^{22}$ De todos modos, los argumentos de Sandel contra el sujeto desencarnado propio de la filosofia liberal son realmente pertinentes y hay una clara contradicción en querer fundar una teoría de la justicia distribuitiva sobre las premisas del individualismo liberal. En este sentido, los liberales como Nozick o Hayek que niegan la existencia misma de semejante concepto son ciertamente más coherentes. ${ }^{23}$ No podemos dejar de estar de acuerdo con Sandel cuando afirma que Rawls no logra justificar de manera convincente la primacía de la justicia y la prioridad del derecho sobre el bien. Pero disentimos cuando saca la conclusión de que eso prueba la superioridad de una política del bien común sobre una política de defensa de los derechos. ${ }^{24}$ El hecho de que la argumentación de Rawls sea inadecuada no implica que su objetivo deba ser rechazado.

Esta cuestión de la prioridad del derecho sobre el bien constituye la verdadera apuesta del debate y va a permitirnos poner en evidencia tanto los límites de la concepción liberal como la ambigüedad de la crítica comunitaria y sus peligros. Como lo hace notar Sandel, para los liberales de tipo kantiano como Rawls la prioridad del derecho sobre el bien significa no sólo que no se pueden sacrificar los derechos individuales en nombre del bienestar general, sino también que los principios de la justicia no pueden ser derivados de una concepción particular de lo que es

\section{Ibid., p. 178.}

22 Rawls pone, en efecto, cada vez más el acento sobre el papel que desempeña en su teoría la concepción kantiana de la persona moral, asi como sobre la prioridad de lo razonable en relación con lo racional. Esto indica que ciertos principios morales están inscritos en la posición original misma y que no se trata más que de una pura teoria de elección racional.

23 Friedrich A. Hayek, Law Legislation and Liberty, volumen 2, Chicago, 1976, p. 69; ver también el libro ya citado de Nozick.

24 Michael J. Sandel, "Morality and the Liberal Ideal", New Republic, 7 de mayo de 1984, p. 166. 
bueno en la vida. ${ }^{25}$ Este es el principio del liberalismo según el cual no puede existir una sola concepción de la eudaimonia, del bienestar, que pueda imponerse a todos, sino que cada uno debetener la posibilidad de bủscar su felicidad como le parezca, fijarse a sí mismo sus propios objetivos y tratar de realizarlos a su manera. Los comentarios, por su parte, afirman que no se puede definir el derecho antes que el bien, pues sólo a través de nuestra participación en una comunidad que define el bien podemos tener un sentido del derecho y una concepción de la justicia. Este es un argumento irreprochable, pero que no autoriza de ningún modo la conclusión de Sandel de que es necesario rechazar la prioridad de la justicia como virtud principal de las instituciones sociales, así como también rechazar la defensa de los derechos individuales, y volver a una política basada en un orden moral común. Semejante conclusión reposa sobre un equívoco fundamental que concierne a la noción misma del bien común, el cual, por otra parte, es creación del propio Rawls. Hasta hace poco ${ }^{26}$ éste insistía en que su teoría de la justicia dependía de la filosofia moral. Ahora bien, su teoría depende por supuesto no de la moral sino de la política y exige distinguir entre el "bien común moral" y el "bien común político". Una vez que semejante distribución ha sido establecida, las consecuencias que extrae Sandel de las incoherencias epistemológicas de Rawls aparecen como inaceptables.

Examinemos este problema más detalladamente. Rawls pretende defender el pluralismo liberal que requiere no imponer a los hombres una concepción del bienestar y un plan de vida particular. La moral individual es para los liberales una cuestión privada y cada uno debe poder organizar su vida como le parezca. De allí viene la importancia de los derechos y el hecho de que los principios de la justicia no pueden privilegiar una concepción particular del bienestar. Pero es evidente que esta prioridad del derecho sobre el bien sólo es posible en un cierto tipo de sociedad con instituciones determinadas, y que no puede haber una prioridad absoluta del derecho sobre el bien, puesto que, como lo afirman con razón los comunitarios, sólo en el interior de una comunidad determinada, la cual se define por el bien que postula, puede existir un individuo con sus derechos. Pero sería necesario especificar que se trata de una comunidad politica, es decir, de un

25 Sandel, Liberalism and the Limits of Justice, op. cit., p. 156.

26 Rawls, "Justice as Fairness: Political not Metaphysical", op. cit., p. 224, donde en la nota 2 reconoce que su concepción de la justicia es política y no moral. 
regimen (en el sentido de politeia) que se define por el bien político que pone en acción. ${ }^{27}$ Ciertos regímenes se caracterizan por el hecho de que no hay distinción entre el bien del hombre y el bien de la ciudad, aunque la separación de esas dos esferas en la modernidad y el rechazo de una concepción única del bien moral no debería hacer perder de vista la existencia del "bien político", el bien que define una asociación política en tanto tal. De este modo, si un régimen liberal democrático debe ser agnóstico en términos de moral, en cambio, no lo es -y no puede serlo- en lo concerniente al bien político, puesto que afirma los principios políticos de la libertad y de la igualdad. Sólo en el interior de semejante régimen, y en función del bien político que lo define, es posible la prioridad de los derechos en relación con las diferentes concepciones del bien moral. Si los comunitarios están autorizados a cuestionar la prioridad del derecho sobre el bien tal como aparece en Rawls, es sin embargo ilegítimo de su parte pretender, como es el caso en Sandel, que eso exige abandonar el pluralismo liberal (así como una política basada en los derechos), dado que semejante prioridad es lo que caracteriza a un régimen liberal democrático.

\section{Moral y política}

Se habrá comprendido que realmente está en cuestión el estatus de lo político y esta discusión revela la incapacidad en que nos encontramos hoy para pensar la política de manera moderna, es decir, de una manera que no sea simplemente instrumental, cosa que implica tomar en cuenta todo lo que tiene que ver con la idea de un "bien político", con la ética propia de lo político, aunque respetando la separación moderna entre moral y política. $\mathrm{Ni}$ Rawls ni Sandel son capaces de pensar esta distinción adecuadamente, aunque por razones diferentes. Sandel, porque su crítica del liberalismo opera a partir de una problemática fundamentalmente aristotélica, en la que todavía no hay separación entre moral y a partir de la cual no podía haber verdadera diferenciación entre "bien común político" y "bien común moral": en la con-

27 Se puede todavía aceptar la definición aristotélica de la comunidad política como una asociación que busca el bien de todos. Pero ese bien debe ser comprendido actualmente en términos exclusivamente políticos como constituido por los principios de una asociación y eso no requiere la existencia de una concepción única del bien moral. Entonces, en una filosofia política moderna se debe hablar de la ética propia de lo político. 
cepción antigua, la política de hecho estaba subordinada a la ética y eso es lo que explica la tendencia de ciertos críticos comunitarios, influidos por Aristóteles, como Sandel o MacIntyre, a creer que para gobernar en función del bien común es necesario fomentar una visión moral única y oponerse al pluralismo liberal. De allí viene su actitud generalmente negativa en relación con la modernidad y su nostalgia por una comunidad orgánica de tipo Gemeinschaft. En cuanto a Rawls, su incapacidad para pensar lo político se explica por el hecho de que éste constituye el punto ciego del liberalismo que tiende a reducirlo a una actividad instrumental. En efecto, todo el aspecto normativo propio de la filosofia política fue desacreditado por el desarrollo de la ciencia política y la distinción positivista entre hechos y valores. De esta manera, toda una serie de cuestiones que son indiscutiblemente de orden político, como la cuestión de la justicia, fueron relegadas al territorio de la moral y por eso, sin duda, Rawls se obstinó durante tanto tiempo en presentar su teoría de la justicia como una contribución a la filosofia morăl.

Esta incapacidad del liberalismo para pensar lo político tiene raíces profundas. Como lo señaló Carl Schmitt, el principio puro y riguroso del liberalismo no puede dar nacimiento a una concepción específicamente política. ${ }^{28}$ En efecto, debe haber negación de lo político en todo individualismo consecuente, puesto que exige que el individuo siga siendo terminus a quo y terminus ad quem. Por eso, según Schmitt, el pensamiento liberal se mueve dentro de la poralidad entre moral y economía, y se limita a querer imponer obligaciones éticas de la política o a someterla a la economía. De allí viene el hecho de que no hay verdadera política liberal, sino solamente una crítica liberal de la política en nombre de la defensa de la libertad individual. ${ }^{29}$

El individualismo liberal no permite concebir el aspecto colectivo de la vida social como constitutivo porque existe una contradicción en el corazón del proyecto de Rawls, como lo indican los comunitarios. Su ambición de fundar racionalmente las exigencias de igualdad (presentes èn el sentido común de las democracias occidentales) a partir de una concepción individualista del sujeto no puede más que fracasar. Y no es el recurso a la moral el que puede aportar la solución para esta limitación fundamen-

28 Carl Schmitt, La notion de politique, 1972, p. 116.

29 Schmitt, op. cit., p. 117. Reconocer la pertinencia de la crítica al liberalismo hecha por Schmitt no implica evidentemente que debamos aceptar su posicion en su totalidad. 
tal del liberalismo. La apelación de Rawls a la concepción kantiana de la persona moral y la introducción de lo razonable junto a lo racional le permiten establecer límites morales a la prosecusión del egoísmo privado, pero sin poner verdaderamente en discusión la concepción individualista. Sólo en el contexto de una tradición que dé realmente un lugar a la dimensión política de la existencia humana y que permita pensar la ciudadanía de otra manera que como simple posesión de derechos se pueden explicar los valores democráticos. Sin embargo, esta crítica del liberalismo debe operarse en el marco de la modernidad y de las conquistas de la revolución democrática. Aun teniendo mucho que enseñarnos, la concepción clásica ya no es practicable. La emergencia del individuo, la separación de la Iglesia y el Estado, el principio de tolerancia religiosa, el desarrollo de la sociedad civil, todos estos elementos han llevado a distinguir el territorio de la moral del de la política. Si bien es importante plantear nuevamente la cuestión del bien común y de la virtud cívica, esto debe hacerse dentro de una problemática moderna, sin postular un bien moral único. No se trata de retroceder más acá del liberalismo, y la crítica del individualismo no implica ni el abandono de la noción de "derechos" ni la del pluralismo.

\section{Justicia y Pluralismo}

En esta dirección se elabora la investigación de Michael Walzer, quien, aunque se coloca del lado de los comunitarios, no se opone a los ideales políticos del liberalismo. Al contrario, su proyecto es defender y radicalizar la tradición liberal democrática. ${ }^{30}$ Walzer se opone al tipo de procedmiento filosófico que supone que un pensador se desprende de todos los lazos con su comunidad a fin de poder descubrir verdades supuestamente universales y eternas. ${ }^{31}$ Según él, un filósofo debe permanecer en la caverna y asumir plenamente su condición de miembro de una comunidad particular, su papel consiste en interpretar, para sus conciudada-

30 Entre los numerosos libros de Michael Walzer aquéllos que tocan más el tema tratado aquí son los siguientes: Obligations. Essays on Desobedience. War and Citizenship, Cambridge, Mass., 1970; Radical Principles: Reflections of an Unreconstructed Democrat, Nueva York, 1980 y sobre todo Spheres of Justice. A defense of Pluralism an Equality, Nueva York, 1983.

31 Walzer, Spheners of Justice, op. cit., p. XIV, así como su artículo"Philosophy and Democracy", Political Theory, vol. 9, No. 3, agosto de 1981, donde presenta su posición sobre este tema de manera más detallada. 
nos, el mundo de significaciones que tienen en común. Si denuncia el racionalismo y el universalismo de la Ilustración y proponerealzar conceptos como los de tradición y comunidad, lo hace para poder defender el ideal democrático de manera más eficaz.

Aunque Walzer critica la posición epistemológica de Rawls, sin embargo está de acuerdo con este último en lo referente a la prioridad de la justicia y la idea de que en nuestras sociedades ésta consiste en la institucionalización de la libertad y de la igualdad. Pero Walzer se distingue de Rawls en su manera de concebir la igualdad, y en Spheres of Justice presenta una teoría pluralista de la justicia social, cuyo objetivo es la realización de lo que llama una "igualdad compleja". De acuerdo con él, es la única concepción de igualdad adaptada a las sociedades modernas, en las cuales el grado de diferenciación está muy avanzado. ${ }^{32}$ Walzer considera, en efecto, que se concibe demasiado a menudo la igualdad a partir del modelo de la igualdad simple, que tiende a igualar lo más posible a las personas en situación global. Semejante visión implica necesariamente una intervención constante del Estado a fin de impedir la emergencia de cualquier forma de dominación. Por lo tanto, abre la vía al totalitarismo que pretende coordinar sistemática y autoritariamente la distribución de todos los bienes en todas las esferas. Por ello, Walzer afirma que si se quiere convertir a la igualdad en objetivo central de una política que también respete la libertad, sólo podemos concebirla como igualdad compleja. ${ }^{33}$ Este tipo de igualdad requiere que diferentes bienes sociales sean distribuidos, no de manera uniforme, sino en función de una diversidad de criterios que refleje la diversidad de esos bienenes sociales y de las significaciones que le son atribuidas. La igualdad es una relación compleja entre personas, mediatizada por una serie de bienes sociales, pero no consiste en una identidad de posesiones. Lo importante es no violar los principios de distribución propios de cada esfera y evitar que el éxito en una esfera implique la posiblidad de ejercer la preponderancia en otras, como ocurre actualmente con la riqueza. Y Walzer cita a Pascal: "la tiranía es querer obtener por una vía lo que no se puede obtener otra. Se rinden diferentes honores a los diferentes méritos: honras de amor a los placeres, de temor a la fuerza, de fe a la ciencian ${ }^{34}$ La justicia, entonces, no es solamente una

32 Walzer, Spheres of Justice, op. cit., p. 316.

33 lbid., p. 18.

34 Pascal, Pensées, Audum, Les Grands Maitres, 1949, p. 128. Este texto es ci- 
cuestión de interpretación y de aplicación de criterios de distribución, sino también de distinciones y de fronteras entre las diferentes esferas. Lo esencial es que ningún bien social pueda servir de medio de dominación, así como es esencial evitar la concentración del poder político, la riqueza, los honores y las funciones particularmente privilegiados en las mismas manos.

El interés de la perspectiva adoptada por Walzer es que permite la crítica del individualismo liberal y de sus presupuestos epistemológicos, conservando al mismo tiempo, e incluso enriqueciendo, el aporte del pluralismo. Esta perspectiva muestra también cómo se puede pensar la justicia sin buscar un punto de vista universal y sin elaborar principios generales válidos para todas las sociedades. Para Walzer, sólo a partir de una comunidad política determinada, y en el interior de la tradición que la constituye y de las significaciones sociales comunes a sus miembros, puede ser planteada la cuestión de la justicia. Según él, no tiene ningún sentido declarar que una sociedad de tipo jerárquico es injusta porque la distribución de los bienes sociales no se efectúa de acuerdo con principios igualitarios. Si la igualdad es un objetivo central para nosotros es porque vivimos en una sociedad liberal democrática, donde las instituciones y las significaciones están profundamente impregnadas por este valor, lo que hace posible su utilización como criterio para juzgar sobre lo justo y lo injusto. En tanto que principios políticos, la igualdad - y la libertad-son susceptibles de numerosas interpretaciones. No puede existir acuerdo definitivo sobre la definición de la libertad y de la igualdad, sobre las relaciones sociales donde esos principios deben ser puestos en acción o su modo de institucionalización. Diferentes filosofias políticas ofrecen interpretaciones diversas de todo ello, pero tal discusión es posible, y el problema de la justicia se plantea para nosotros"en estos términos, porque esos valores son centrales para nuestra tradición.

\section{¿Aristóteles o Maquiavelo?}

A la concepción liberal del individuo, los autores comunitarios oponen la imagen del ciudadano que se encuentra en la tradición del republicanismo cívico. Contrariamente al liberalismo, esta tradición proporciona, en efecto, un lenguaje que permite pensar la política de una manera no instrumental. Puesto que ha desempeñado un papel importante en la cultura política nor-

tado en Spheres of Justice, p. 18. 
teamericana del siglo XVIII y que no ha desaparecido completamente, se tratará entonces de revivificarla y devolver de esta manera a los norteamericanos la capacidad de articular sus experiencias y concebir su identidad en términos de su participación activa en una comunidad política. Los comunitarios ven la solución para la crisis de legitimidad que afecta al sistema democrático en una revalorización de la esfera de lo político y en una rehabilitación de la noción de "virtud política".

El problema reside en -la ambigüedad de esta noción de "humanismo cívico" o de "republicanismo cívico" tal como ha sido recientemente elaborada. Esta mezcla de elementos aristotélicos y maquiavélicos puede, en efecto, dar lugar a interpretaciones extremadamente diferentes, según que se acepte con Aristóteles la unicidad del bien y la ausencia de distinción entre ética y política o que, siguiendo a Maquiavelo, se distingan esos dos territorios y se insista sobre el papel central de los conflictos en la preservación de la libertad. Ya he indicado de qué manera, en autores como Sandel o MacIntyre, la crítica del liberalismo conduce a un callejón sin salida en lo que se refiere a las características de la democracia moderna y conduce al rechazo de la modernidad. ${ }^{35}$ No es el caso de Taylor o de Walzer, que se esfuerzan por integrar ciertos aportes del liberalismo: no se trata pues, de una problemática intrínsecamente antimoderna, como lo afirman ciertos liberales. 36 .

Sin embargo, a falta de la elaboracióndeun modelorepublicano adecuado a las exigencias de la democracia moderna, el entusiasmo actual por el republicanismo cívico sólo puede dar lugar a confusiones de consecuencias nefastas para todos aquéllos que defienden la extensión de los derechos y de las prácticas democráticas. Es fundamental distinguir entre "conciencia cívica", es decir, exigencias propias de todo ciudadano en un régimen liberal democrático, donde los criterios de justicia son los de la libertad, la igualdad y la postulación de un bien común sustantivo, que impondría a todos una concepción única de eudaimonia. Conciencia cívica no implica que necesariamente deba haber consenso, y el ideal republicano no requiere la supresión de la diversidad en fa-

35 Se podría decir lo mismo de la posición de Hannah Arendt cuya relexión se inscribe también en la tradición del republicanismo, a pesar de que su obra no desempeña un papel muy importante en el debate actual en los Estados Unidos.

36 Ver por ejemplo, H. Hirsh, "The Threnody of Liberalism" y D. Herzog, "Some questions for Republicans", ambos en Political Theory, vol. 14, No. 3, agosto de 1986 . 
vor de la unidad. Una concepción republicana que se inspire en Maquiavelo, aunque también en Montesquieu, Tocqueville y Stuart Mill, puede perfectamente asimilar lo que constituye la gran contribución del liberalismo: la separación de lo público y de lo privado y la defensa del pluralismo. Pero eso exige concebir la ciudadanía de manera democrática, es decir, sin renunciar a la libertad individual. Ahora bien, una tarea semejante sólo es posible si se logra conceptualizar la libertad de otra manera que no sea la defensa de los derechos individuales contra el Estado, cuidándose al mismo tiempo de no sacrificar al individuo en nombre del ciudadano.

\section{Libertad de los antiguos o libertad de los modernos}

Los trabajos fundados en la "nueva historia", inspirada por Quentin Skinner, son particularmente pertinentes para semejante proyecto. En un artículo, donde hace un balance sobre los resultados de este tipo de investigaciones, Pocock indica cómo en los orígenes del pensamiento político moderno se encuentran dos estilos de lenguaje político, de los cuales uno va a llegar a imponerse en detrimento del otro. ${ }^{37}$ Por una parte, existe el lenguaje de la virtud, que es el del republicanismo clásico, y por otra, el lenguaje del derecho que expresa el paradigma del derecho natural y que se encuentra en la jurisprudencia. El término libertas está presente en los dos lenguajes, pero con un sentido diferente. En el lenguaje de los juristas, libertas tiene el sentido de imperium, libertad de practicar las propias leyes. La libertad del ciudadano consiste entonces en dedicarse a sus propios asuntos bajo la protección de la ley. Por el contrario en el lenguaje republicano se insiste en la libertad en el sentido de participación en el gobierno del Estado, ligada a una concepción del hombre como animal político que sólo realiza su naturaleza a través de sus actividades en el dominio público. Esas dos formas coexistieron durante un cierto tiempo y Skinner mostro, en el primer volumen de The Foundations of Modern Political Thought, 38 cómo la lucha por la independencia de las repúblicas italianas había sido llevada a cabo simultáneamente en el lenguaje republicano y en el de los juristas. A continuación, el lenguaje del derecho natural suplantaría al de la virtud, pero al lado de la historia del liberalismo, centradas sobre la

37 Pocock, Virtue, Commerce and History, op. cit., capítulo 2.

38 Quentin Skinner, The Foundations of Modern Political Though, 2 volumenes, Cambridge, 1978. 
ley y el derecho habrá, durante todo el comienzo del periodo moderno, una historia del humanismo republicano donde la personalidad será concebida en términos de virtud. Solamente con Hobbes se impone el modo de razonamiento político individualista para el cual la libertad se limita a la defensa de los derechos individuales.

El objetivo de Skinner en sus trabajos más recientes ${ }^{39}$ es volver a poner en lugar de honor a esta concepción republicana que durante el Renacimiento en Europa reformuló la concepción romana clásica del ciudadano, pues considera que puede proporcionarnos una concepción de la libertad más adecuada que la concepción liberal. Es perfectamente consciente del problema que plantea hoy la relación entre libertad individual y libertad política. En efecto, desde Benjamín Constant, se admite generalmente que la "libertad de los modernos" consiste en el goce apacible de la independencia privada y que ello implica la renuncia a la "libertad de los antiguos", a la participación activa en el poder colectivo, pues eso conduce a someter el individuo a la comunidad.

Esta misma tesis ha sido reformulada en un artículo célebre por Isaiah Berlin, ${ }^{40}$ quien distingue entre la concepción "negativa" de la libertad, entendida simplemente como ausencia de coersión, que exige que una porción de la existencia humana permanezca independiente de la esfera del control social, y la concepción "positiva" de la libertad, la cual proviene del deseo del individuo de ser su propio amo e implica la idea de realización y logro de la verdadera naturaleza humana. De acuerdo con Berlin, esta segunda concepción es potencialmente totalitaria para un liberal, y de ello saca la conclusión de que la idea de democracia y de autogobierno no puede formar parte de la idea liberal de libertad. Afirma que toda concepción positiva de la libertad es antimoderna, pues requiere la postulación de la existencia de una noción objetiva del bienestar para el hombre. De esta manera, todos aquellos que defienden la concepción republicana de la libertas, la idea de que la libertad no puede ser asegurada más que en una comunidad que se autogobierna, aparecen como adversarios de la modernidad.

39 Q. Skinner, "The idea of negative Liberty: philosophical and historical perspectives", en R. Rorty, J. B. Scheenwind y Q. Skinner, Philosophy in History, Cambridge, 1984.

40 Isaiah Berlin, "Two Concepts of Liberty" en Four Essays on Liberty, Oxford, 1969. 
Skinner rechaza esta tesis y se esfuerza por probar que en la tradición del republicanismo cívico, y más particularmente en Maquiavelo, se encuentra una concepción de la libertad que es a la vez negativa, pues no implica una noción objetiva de la eudaimonia, pero que sin embargo incluye los ideales de participación política y de virtud cívica. De esta manera, en los Discorsi, Maquiavelo propone una concepción de la libertad como capacidad para los hombres de perseguir sus propios objetivos, sus humori, afirmando al mismo tiempo que con el fin de asegurar las condiciones necesarias para evitar la coerción y la servidumbre, que harían imposible el ejercicio de esta libertad individual, es indispensable que los hombres cumplan con ciertas funciones públicas y cultiven las virtudes requeridas. Para Maquiavelo es necesario practicar la virtud cívica y servir al bien común, a fin de garantizarnos el grado de libertad personal que nos permitirá perseguir nuestros propios fines. ${ }^{41}$

Semejante línea argumental requiere, por supuesto, de desarrollos posteriores, pero indica una vía extremadamente fecunda. La tarea principal de una filosofía política moderna y democrática es precisamente la articulación de la libertad individual y de la libertad política, pues allí es donde se juega toda la cuestión de una ciudadanía pluralista y democrática. El gran mérito de Skinner es abrirnos una pista y remitirnos a Maquiavelo. Éste representa indiscutiblemente un punto de referencia fundamental para aquéllos que quieren pensar lo político actualmente, y si es importante reanudar los lazos con la tradición del republicanismo cívico, también es esencial que sea bajo su égida. La crítica comunitaria del liberalismo puede conducirnos de esta manera a redescubrir una vía abierta hace varios siglos. ya, pero cuyas potencialidades todavía no han sido explotadas, porque la reflexión sobre la política iba a comprometerse con Hobbes en la dirección supuestamente científica que culminó con el rechazo de sus aspectos normativos y el predominio de la concepción instrumental. 